DOI: https://doi.org/10.46667/renbio.v13i1.337

\title{
Percepções docentes e práticas de ensino de ciências e biologia na pandemia: uma investigação da Regional 2 da SBEnBio
}

\author{
Science and biology teaching practices and perceptions in the pandemic times: \\ an SBEnBio section 2 investigation
}

\author{
Rodrigo Cerqueira do Nascimento Borba ${ }^{1}$; Pedro Pinheiro Teixeira ${ }^{2}$; \\ Karine de Oliveira Bloomfield Fernandes ${ }^{3}$; Maína Bertagna ${ }^{4}$; Cristiana Rosa Valença ${ }^{5}$; \\ Lucia Helena Pralon de Souza ${ }^{6}$
}

\begin{abstract}
Resumo
O artigo apresenta e discute uma iniciativa promovida pela Regional 2 (RJ/ES) da Associação Brasileira do Ensino de Biologia (SBEnBio) para compreensão das práticas de ensino de Ciências e Biologia desenvolvidas por docentes durante o isolamento social determinado pela pandemia de COVID-19 no período compreendido entre março e abril de 2020. Aplicamos um questionário on-line a 187 respondentes. Os resultados indicam que demandas metodológicas sobre planejamento, avaliação e estratégias didáticas constituíram os principais desafios nesta conjuntura. Destaca-se também o aumento da carga de trabalho e as dificuldades de acesso à internet de seus estudantes. Concluímos que é um momento árduo para a maioria dos docentes, mas que associações como a SBEnBio podem criar espaços para reflexão sobre essas práticas.
\end{abstract}

Palavras chave: docência; ensino remoto; COVID-19.

\begin{abstract}
The paper presents and discusses a study promoted by Regional 2 (RJ / ES) of the Brazilian Biological Education Association (SBEnBio) on the Science and Biology teaching practices developed by teachers during the social isolation determined by the pandemic of COVID-19 in the period between March and April 2020. We applied an online questionnaire to 187 respondents. The results indicate that methodological demands on planning, evaluation and didactic strategies were the main challenges in this context. Moreover, respondents reported greater workload and most students as having difficulties to access the internet. We conclude that it is a hard time for most teachers, but that associations like SBEnBio can create spaces for reflection on these practices.
\end{abstract}

Keywords: teaching; remote teaching; COVID-19.

\footnotetext{
${ }^{1}$ Doutorando em Educação - Universidade Federal do Rio de Janeiro (URJ). Rio de Janeiro, RJ - Brasil. Mestre em Educação - Universidade Federal Fluminense (UFF). Rio de Janeiro, RJ - Brasil. Secretário da SBEnBio Regional 2. Professor de Ciências e Biologia Redes particular e pública. Rio de Janeiro, RJ - Brasil. E-mail: rodrigocnb@gmail.com

${ }^{2}$ Doutor em Ciências Humanas - Pontifícia Universidade Católica do Rio de Janeiro (PUC-Rio). Rio de Janeiro, RJ - Brasil. Conselheiro da SBEnBio - Regional 2. Professor - Pontifícia Universidade Católica do Rio de Janeiro (PUC-Rio). Rio de Janeiro, RJ - Brasil. E-mail: pedro.teixeira@ puc-rio.br

${ }^{3}$ Doutora em Educação pela Universidade Federal do Rio de Janeiro (UFRJ). Rio de Janeiro, RJ -

Brasil. Diretora da SBEnBio - Regional 2. Professora - Colégio Universitário Geraldo Reis da Universidade Federal Fluminense (UFF). Niterói, RJ - Brasil. E-mail: kabloom01@gmail.com

${ }^{4}$ Doutora em Educação - Universidade Estadual de Campinas (UNICAMP). Campinas, SP - Brasil. Conselheira da SBEnBio - Regional 2. Professora - Instituto de Educação de Angra dos Reis da Universidade Federal Fluminense (UFF). Niterói, RJ - Brasil. E-mail: mainabertagna@id.uff.br

${ }^{5}$ Doutora em Educação de Ciências e Saúde - Universidade Federal do Rio de Janeiro (UFRJ). Rio de Janeiro, RJ - Brasil. Conselheira da SBEnBio - Regional 2. Professora de Biologia - Centro Federal de Educação Tecnológica Celso Suckow da Fonseca (CEFET/RJ). Rio de Janeiro, RJ - Brasil. E-mail: crisvalmac@yahoo.com.br

${ }^{6}$ Doutora em Educação em Ciências e Saúde - Universidade Federal do Rio de Janeiro. Rio de Janeiro, RJ Brasil. Conselheira da SBEnBio - Regional 2. Professora da Escola de Educação e do PPGEdu - Universidade Federal do Estado do Rio de Janeiro (UNIRIO). Rio de Janeiro, RJ - Brasil. E-mail:

luciapralon2@yahoo.com.br
}

Submetido em: 14/06/2020 - Aceito em: 19/06/2020

REnBio - Revista de Ensino de Biologia da SBEnBio - ISSN: 1982-1867 - vol. 13, n. 1, p. 153-171, 2020 
DOI: https://doi.org/10.46667/renbio.v13i1.337

\section{Introdução}

SARS-CoV-2. COVID-19. Pandemia do novo coronavírus. Três termos que marcam o ano de 2020 de diferentes formas, produzindo sentidos, sensações e emoções múltiplas para diferentes sujeitos, sociedades e culturas. Enclausurados em suas residências, milhares de professores encontram-se às voltas com o drástico tensionamento dos modelos de docência que conheciam, praticavam e nos quais se constituíram profissionais da educação. Ao passar de exíguos dias, condicionados por diferentes pressões dos estudantes, das famílias, dos gestores escolares, deixaram os papéis de consumidores das mídias e redes sociais para tornarem-se produtores de artefatos consubstanciados com a mesma matéria digital que pavimenta o mundo virtual.

Como? O que? Quando? Por que? Para quem? Questões que antes permeavam os momentos de planejamento e avaliação das práticas educativas direcionando os diferentes saberes e fazeres pedagógicos na realidade presencial agora assumem outros sentidos, inéditos para a maior parte do professorado. Enquanto as Ciências da Vida tentam elaborar meios para que as populações sobrevivam ao agente viral infeccioso que se alastra sem respeitar fronteiras, são simultaneamente alvejadas por cortes nos financiamentos de pesquisas, extinção de bolsas para a formação e limitações no custeio de pesquisadores. Arrematando a composição deste cenário aterrador para profissionais da educação e da saúde, a ascensão do ódio aos princípios democráticos e do negacionismo científico aos espaços de tomada de decisões políticas em diferentes esferas governamentais chacoalha o país.

Nesta dura conjuntura para professores de Ciências e Biologia - que além de darem conta do trabalho com os conteúdos e conhecimentos consagrados das disciplinas escolares que lecionam, correm o risco de serem taxados como doutrinadores se desmentirem figuras públicas -, é que se desenvolveram as ações apresentadas neste relato. Cada vez mais contestada e tolhida, seja pelas pressões em nome de "resultados eficazes" para os processos de ensino e de aprendizagem, seja pela vigilância moral e ideológica que instila censura e coage o labor professoral, a autonomia docente está cada vez mais sendo disputada nos cotidianos escolares e nas políticas de currículo que tendem a subalternizar o trabalho dos professores (SELLES e ANDRADE, 2016).

Diante de tal realidade, nós, da Regional 2 (RJ/ES) da Associação Brasileira de Ensino de Biologia (SBEnBio), nos perguntamos: De que maneira podemos ajudar os colegas professores de Ciências e Biologia atuantes na Educação Básica nesse momento? O primeiro passo seria conhecer melhor essa realidade e saber, desses docentes que estão atuando remotamente, como estão lidando com essas mudanças e quais são suas maiores dificuldades. Somente escutando esse grupo teríamos condições, enquanto Associação, de promover ações que de fato fossem uma contribuição positiva nesse cenário.

Para isso, foi elaborado um questionário com o objetivo de investigar as experiências, os desafios, as expectativas e as necessidades de docentes e futuros docentes de Ciências e Biologia da Educação Básica, diante do atual cenário de pandemia e distanciamento social, 
DOI: https://doi.org/10.46667/renbio.v13i1.337

cujos resultados apresentamos nesse texto. Nosso intuito não é assumir uma postura prescritiva, pautada em informar roteiros para elaboração e realização de atividades para ensino remoto ou dar soluções mágicas aos dilemas e desafios vividos pelos professores. Contudo, temos consciência de que, vivenciando diferentes contextos, esses docentes encontram e praticam diferentes modos de produção de conhecimentos escolares que respondem aos saberes estudantis e às demandas da escolarização, conforme ponderam Carmo e Selles (2018).

A despeito da disputa de narrativas instaurada no meio acadêmico, favoráveis ou contrárias à substituição das aulas presenciais pelas aulas remotas - que tecem considerações a respeito da viabilidade dessas práticas nos diferentes cenários que a realidade material e cultural dos estudantes e professores pode apresentar, sobre sua caracterização ou não como Educação à Distância $(\mathrm{EaD})$ e sobre o potencial de precarização do trabalho docente que possam estar promovendo -, o fato é que elas estão acontecendo e precisamos lidar com isso. Sem parâmetros prévios que possam orientar essas práticas, os professores estão produzindo aulas remotas sozinhos.

Neste artigo, relatamos o processo de construção dessa pesquisa e apresentamos algumas reflexões relacionadas aos principais pontos indicados pelos docentes que participaram da mesma. Nosso objetivo principal é publicizar os resultados, problematizá-los a luz de questões que têm atravessado o trabalho docente em meio à pandemia e fornecer pistas para que um movimento que dê suporte formativo aos professores seja erigido de modo coletivo. Assim, o texto se organiza da seguinte maneira: em uma primeira parte, apresentamos as questões que nortearam o levantamento realizado a partir do questionário respondido pelos docentes associados à Regional 2 da SBEnBio e outros professores e pesquisadores. Na segunda, discorremos sobre a análise das respostas às vinte e duas questões realizadas. E, por fim, tecemos as considerações finais, revisitando o texto e apresentando os desdobramentos do levantamento realizado. 
DOI: https://doi.org/10.46667/renbio.v13i1.337

\section{Procedimentos da pesquisa e metodologia}

Os procedimentos da pesquisa buscaram fornecer subsídios para que as seguintes questões pudessem ser interpretadas colaborativa e propositivamente: o que professores e professoras de Ciências e Biologia estão fazendo durante a pandemia? Quais práticas e atividades de ensino estão desenvolvendo ou utilizando? Quais são as dificuldades e os desafios mais proeminentes para a formação e a profissão docente no contexto de quarentena? Como a Regional 2 da SBEnBio pode contribuir para apoiar o trabalho docente em Ciências e Biologia nesse momento?

Buscando alcançar o maior número de participantes em um curto período de tempo, optamos por obter essas informações a partir de um questionário hospedado na plataforma Google Formulários. A construção do questionário foi realizada pelos autores deste trabalho entre os dias 23 e 24 de abril de 2020. Foi realizado um pré-teste da versão preliminar com onze professores de diferentes redes da Educação Básica membros de nossas redes de contato. Suas sugestões sobre a redação das questões e de possibilidades de respostas foram incorporadas à versão final do questionário.

O questionário foi aplicado entre os dias 25 e 30 de abril de 2020. Sua formulação definitiva contém 22 perguntas organizadas em três seções: (1) formação acadêmica e profissional do docente; (2) ensino remoto; (3) ações da SBEnBio. A divulgação ocorreu por meio de convites enviados por e-mail aos filiados à Regional 2 da SBEnBio, bem como por mensagens compartilhadas por aplicativos de mensagens virtuais e via publicações, abertas ao acesso de qualquer pessoa, realizadas pelo perfil da Regional em uma rede social de amplo alcance $^{7}$. O grupo de respondentes foi formado por 187 respondentes $^{8}$.

Para a definição da amostra foi utilizada a técnica "bola de neve" com fins exploratórios. Trata-se de um método de amostragem não probabilística, que utiliza cadeias de referência, auxiliando no estudo de populações de difícil acesso e cuja quantidade de participantes também é de difícil estimativa e precisão (VINUTO, 2004). No caso desta pesquisa, por conta do contexto de isolamento social devido à pandemia de COVID-19, a única forma de acesso aos professores de Ciências e de Biologia foram as redes sociais e e-mails.

Como principal desafio desta abordagem, destacamos a amostragem de participantes não randomizada. Isso se explica por que os autores divulgaram o formulário dentro de suas redes de contatos pessoais e pela lista de e-mails da Regional 2. O intuito foi propiciar que a coleta de dados e a produção de um relatório da pesquisa fossem realizados de modo ágil e efetivo para a comunidade de docentes atendida pela Associação. A interpretação dos resultados foi feita com base nas respostas obtidas em diálogo com autores do campo educacional e somadas às reflexões oriundas de nossas experiências prévias com investigações

\footnotetext{
${ }^{7}$ A Regional 2 da SBEnBio mantém uma página no Facebook que pode ser acessada em: https://www.facebook.com/sbenbio2/.

${ }^{8}$ Houve 192 respondentes no total, entretanto, 5 não autorizaram a divulgação de seus dados.
} 
DOI: https://doi.org/10.46667/renbio.v13i1.337

acadêmicas em escolas. Os dados obtidos nos questionários foram organizados e analisados por meio de gráficos e tabelas do Google Formulários, Excel e do programa de análise de dados estatísticos SPSS, versão 25.

\section{Resultados e discussão}

Apresentaremos e analisaremos a seguir, os resultados de acordo com as seções do questionário.

\section{Seção 1: formação acadêmica e profissional}

Participaram da pesquisa docentes que lecionam Ciências e/ou Biologia em diferentes segmentos da Educação Básica: Anos Iniciais do Ensino Fundamental I (EFI), Anos Finais do Ensino Fundamental (EF2), Ensino Médio (EM) e pré-vestibulares. Não averiguamos a atuação em diferentes modalidades de ensino, tais como Educação de Jovens e Adultos ou Educação no Campo. A maior parte dos participantes $(80,2 \%)$ reside no estado do Rio de Janeiro, conforme o quadro 1. Acreditamos que a predominância de respondentes do estado do Rio de Janeiro, deveu-se à forma como a amostra foi constituída (técnica de amostragem "bola de neve"), ou seja, os contatos iniciais de divulgação do questionário partiram da equipe de professores e pesquisadores da Regional 2 da SBEnBio e estes contatos divulgaram para outros. Também destacamos que a maioria não era associada à SBEnBio $(85,6 \%)$ e atuava no Ensino Médio (55,5\%) e/ou nos Anos Finais do Ensino Fundamental (45,5\%), considerando que os respondentes podiam ocupar mais de um cargo e assim optar por mais de uma alternativa para esta questão 9 .

\footnotetext{
${ }^{9}$ Estes dados se referem à questão: "Você atua (pode marcar mais de uma opção): 1) rede pública municipal, 2) rede pública estadual, 3) rede pública federal, 4) rede particular, 5) outras".
} 
DOI: https://doi.org/10.46667/renbio.v13i1.337

Quadro 1 - Frequência de participantes por unidades da federação.

\begin{tabular}{|c|c|}
\hline UF & $\%$ \\
\hline Rio de Janeiro & 80,2 \\
\hline São Paulo & 7,5 \\
\hline Paraná & 4,3 \\
\hline Minas Gerais & 2,1 \\
\hline Espírito Santo & 1,6 \\
\hline Bahia & 1,1 \\
\hline Amazonas & 0,5 \\
\hline Ceará & 0,5 \\
\hline Distrito Federal & 0,5 \\
\hline Goiás & 0,5 \\
\hline Paraíba & 0,5 \\
\hline Pernambuco & 0,5 \\
\hline Total & $\mathbf{1 0 0}$ \\
\hline
\end{tabular}

Fonte: Autores.

Indagados se estavam realizando atividades remotas durante o período de isolamento, cerca de metade $(47,7 \%)$ dos respondentes afirmaram que estavam efetivamente produzindo atividades e materiais para aulas remotas, $20 \%$ dos professores afirmaram que estavam interagindo com os estudantes mas não exatamente elaborando aulas remotas, e cerca de 30\% não estavam realizando nenhuma atividade remota. Por se tratar de uma pesquisa realizada no início do período de isolamento social (março e abril de 2020), acreditamos que estes resultados poderiam ser outros, caso o questionário fosse aplicado nos meses de maio e junho de 2020.

Devido à suspensão das aulas presenciais, alguns decretos foram sendo elaborados por governadores e prefeitos no que se refere à adoção do ensino remoto nos sistemas educacionais. No estado do Rio de Janeiro, por exemplo, quase todas as escolas da rede particular de ensino desde o decreto $\mathrm{n}^{\mathrm{o}} 46.973$ de 16 de março de $2020^{10}$ iniciaram o planejamento e a execução de atividades remotas para seus alunos. Nesse contexto, os colégios estaduais seguiram o mesmo movimento a partir do início de abril, após a Secretaria de Educação do Estado do Rio de

\footnotetext{
${ }^{10}$ Revogado pelo decreto $\mathrm{n}^{\circ} 47.003$ de 27 de março de 2020, que "prorroga medidas, anteriormente, adotadas e estabelece novas medidas temporárias de prevenção ao contágio e de enfrentamento da emergência em saúde pública de importância internacional, decorrente do novo coronavírus, vetor da COVID-19, bem como, reconhece a necessidade de manutenção da situação de emergência no âmbito do Estado do Rio de Janeiro”.
} 
DOI: https://doi.org/10.46667/renbio.v13i1.337

Janeiro (SEEDUC/RJ) adiantar o período de recesso de julho para as duas últimas semanas de março.

Com o parecer do Conselho Nacional da Educação (PARECER CNE/CP n ${ }^{\circ}$. 5/2020, aprovado em 28 de abril e homologado pelo Ministério da Educação em 29 de maio), a SEEDUC/RJ adotou definitivamente, no início de maio, o ensino remoto na rede estadual, apesar das críticas e das poucas oportunidades de discussão sobre o acesso democrático à internet por professores e estudantes, a falta de preparo específico para o uso das ferramentas on-line, entre outras questões. Segundo o Fundo das Nações Unidas para a Infância (UNICEF) $^{11}$, em 2019, 4,8 milhões de crianças e adolescentes de 9 a 17 anos de idade viviam em domicílios sem acesso à internet no Brasil, totalizando $17 \%$ dessa população. Os riscos de exclusão digital e seus motivos foram elencados por diferentes entidades, como o Sindicato Estadual dos Profissionais da Educação do Rio de Janeiro (SEPE/RJ) ${ }^{12,13,14}$ e a SBEnBio ${ }^{15,16}$.

Desse modo, podemos ver no Gráfico 1, o resultado da influência direta dessas políticas públicas lançadas sobre as escolas. Ao perguntarmos, dentre as redes de ensino que os respondentes trabalhavam, quais estavam utilizando atividades remotas, as redes estadual e privada foram as mais apontadas pelos respondentes como aquelas que, já no início da pandemia, solicitaram aos professores o planejamento e a execução de atividades para o ensino remoto.

\footnotetext{
${ }^{11}$ Cf. Comunicado da UNICEF à imprensa. Disponível em:

$<$ https://www.unicef.org/brazil/comunicados-de-imprensa/unicef-alerta-essencial-garantir-acesso-livre-ainternet-para-familias-e-criancas-vulneraveis>. Acesso em 13 de jun. de 2020.

${ }^{12}$ Cf. Nota conjunta das entidades estudantis secundaristas e dos trabalhadores da educação em repúdio ao EAD e ao corte de auxílios. Disponível em: 〈http://www.seperj.org.br/ver_noticia.php?cod_noticia=22167>. Acesso em 14 de jun. de 2020.

${ }^{13} \mathrm{Cf}$. Nota do SEPE/RJ sobre assédios relativos à obrigatoriedade de realização de atividades remotas na rede municipal do Rio de Janeiro. Disponível em: 〈http://www.seperj.org.br/ver_noticia.php?cod_noticia=22166>. Acesso em 14 de jun. de 2020.

${ }^{14}$ Cf. Posição do SEPE/RJ sobre o Plano de Ação Pedagógica da SEEDUC. Disponível em: <http://www.seperj.org.br/ver_noticia.php?cod_noticia=22152>. Acesso em 14 de jun. de 2020

${ }^{15} \mathrm{Cf}$. Posicionamento ao parecer do CNE que trata da reorganização dos calendários escolares. Disponível em: $<$ https://sbenbio.org.br/geral/posicionamento-ao-parecer-do-cne-que-trata-da-reorganizacao-dos-calendariosescolares/>. Acesso em 14 de jun. de 2020.

${ }^{16}$ Cf. SBEnBio apoia o posicionamento da REPU e do GERUD, em relação ao ensino não presencial. Disponível em: <https://sbenbio.org.br/geral/sbenbio-apoia-o-posicionamento-da-repu-e-do-gerud-em-relacaoas-ensino-nao-presencial/>. Acesso em 14 de jun. de 2020.
} 
Gráfico 1 - Contagem das respostas à pergunta "Das redes que você trabalha, indique quais têm utilizado atividades remotas de ensino?".

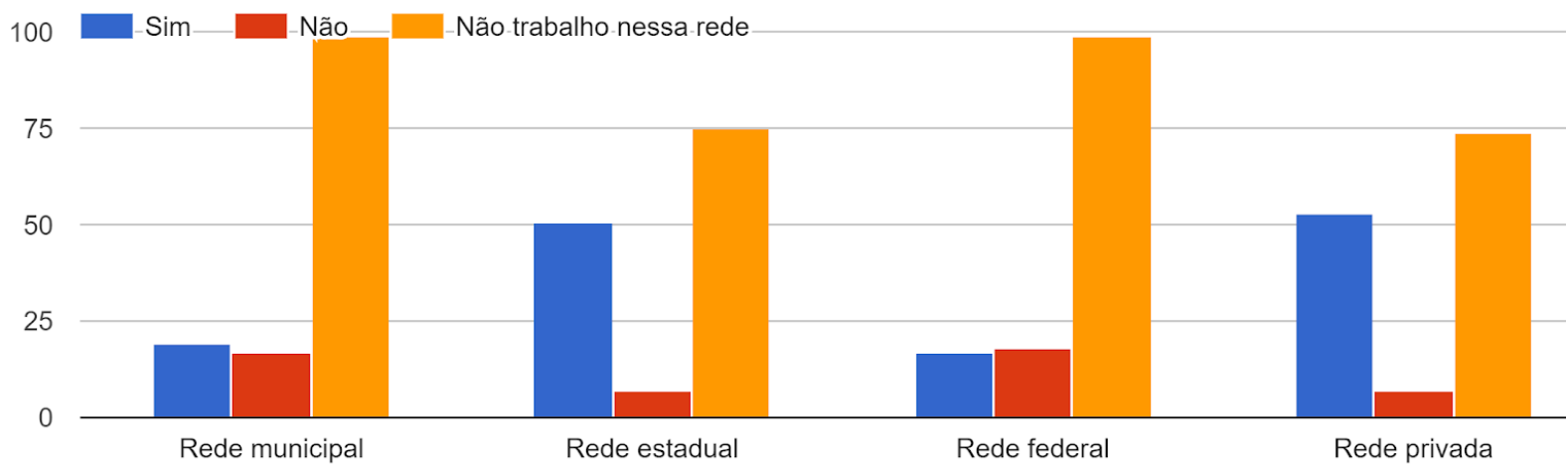

Fonte: Autores.

Acreditamos que, no caso da rede privada de ensino, pode ter havido pressão dos pais para que as escolas se posicionassem e tomassem medidas frente à suspensão das atividades presenciais, evitando prejuízo financeiro e pedagógico dos seus alunos. Na rede pública estadual, as decisões sobre a suspensão das aulas in loco e a adoção de aulas remotas nesta rede de ensino foram determinadas e, de certa forma, impostas pela SEEDUC/RJ, desde final de março de 2020 e início de abril. Segundo a Correspondência Interna CI SEEDUC/COMED SEI $n^{\circ}$ 6, foi estabelecida uma parceria da SEEDUC/RJ com a empresa Google For Education com a intenção de viabilizar e dar continuidade aos estudos dos alunos da rede estadual.

Uma pesquisa realizada pelo Instituto Península de 23 a 27 de março de 2020, com aplicação de questionário on-line a 2400 professores da rede pública e privada do Brasil investigou os sentimentos e percepções dos educadores brasileiros naquele momento da pandemia ${ }^{17}$. Foi encontrada uma diferença entre a percepção dos professores sobre o ensino remoto entre as redes pública e particular de ensino. Segundo a pesquisa, professores que atuavam na rede privada pareciam estar mais preparados com a interação remota, quando comparados aos docentes das redes estaduais e municipais; as redes privadas de educação aparentavam oferecer mais suporte à distância aos alunos; e dentre as redes públicas, as estaduais apresentaram maior capacidade de suporte à distância (INSTITUTO PENÍNSULA, 2020). No que se refere a produção de atividades remotas por segmento, tivemos mais respondentes que atuavam o Ensino Fundamental 2 e o Ensino Médio, conforme quadro 2:

\footnotetext{
${ }^{17}$ Esta pesquisa continua a ser conduzida, visando explorar os diferentes momentos da pandemia e possíveis mudanças entre eles.
} 
DOI: https://doi.org/10.46667/renbio.v13i1.337

Quadro 2: Frequência de docentes por segmento que declararam produzir atividades remotas.

\begin{tabular}{|c|c|c|c|c|}
\hline & EF1 $(\mathbf{n}=\mathbf{1 0})$ & EF2 $(\mathbf{n}=\mathbf{7 1})$ & EM $(\mathbf{n}=\mathbf{8 9})$ & PV $(\mathbf{n = 2 3})$ \\
\hline Não & $20,0 \%$ & $15,5 \%$ & $15,7 \%$ & $17,4 \%$ \\
\hline Sim & $80,0 \%$ & $84,5 \%$ & $84,3 \%$ & $82,6 \%$ \\
\hline
\end{tabular}

Fonte: Autores. EF1: Anos Iniciais do Ensino Fundamental; EF2: Anos Finais do Ensino Fundamental; EM: Ensino Médio; PV: Pré-vestibular

Para o Ensino Médio esse resultado era esperado, uma vez que, no Rio de Janeiro, esse segmento fica à cargo do governo do Estado e, como ressaltado anteriormente, a SEEDUC/RJ instituiu o ensino remoto. Contudo, cabe reconhecer um limite explicativo da pesquisa. Uma vez que os respondentes poderiam atuar em mais de um segmento, não podemos afirmar com certeza para quais segmentos eles estavam produzindo essas atividades. Assim, se um professor atua no Ensino Fundamental 2 e no Ensino Médio, não é possível afirmar se ele estava realizando atividades para ambos ou apenas para um deles. Essa consideração vale para todos os itens que são analisados por segmentos.

\section{Seção 2: ensino remoto}

A segunda seção do questionário trata das atividades remotas produzidas pelos respondentes. Conforme o quadro 3 e devido à maior presença de professores na amostra para os segmentos do Anos Finais do Ensino Fundamental e Ensino Médio, optamos por destacar as produções nestes dois segmentos, sendo elas: listas de exercícios e estudos dirigidos e o uso de ambientes virtuais como materiais e atividades mais utilizados pelos professores participantes.

Acreditamos que, pelos dados desta pesquisa serem coletados no início do período de isolamento social, os professores, quando solicitados pelas redes de ensino, utilizaram conhecimentos e recursos didático-pedagógicos que já possuíam para atender as demandas iniciais de ensino remoto, buscando produzir, em seus contextos de trabalho, saberes que eles compreendem e dominam (TARDIF, 2014). 
DOI: https://doi.org/10.46667/renbio.v13i1.337

Quadro 3 - Atividades e materiais produzidos por segmento de ensino.

\begin{tabular}{|c|c|c|c|c|}
\hline Atividades & $\begin{array}{c}\mathrm{EF} 1 \\
(\mathrm{n}=11)\end{array}$ & $\begin{array}{c}\mathrm{EF} 2 \\
(\mathrm{n}=62)\end{array}$ & $\begin{array}{c}\mathrm{EM} \\
(\mathrm{n}=77)\end{array}$ & $\begin{array}{c}\mathrm{PV} \\
(\mathrm{n}=19)\end{array}$ \\
\hline Listas de exercícios / Estudos dirigidos & $100,0 \%$ & $85,5 \%$ & $81,8 \%$ & $94,7 \%$ \\
\hline $\begin{array}{l}\text { Uso ambientes virtuais de aprendizagem (Ex.: } \\
\text { Moodle, Google Classroom). }\end{array}$ & $88,9 \%$ & $80,6 \%$ & $75,3 \%$ & $68,4 \%$ \\
\hline $\begin{array}{l}\text { Vídeos e documentários no YouTube (ou } \\
\text { outros sites semelhantes) }\end{array}$ & $66,7 \%$ & $61,3 \%$ & $70,1 \%$ & $57,9 \%$ \\
\hline Textos de divulgação científica & $22,2 \%$ & $33,9 \%$ & $49,4 \%$ & $31,6 \%$ \\
\hline Estou dando aulas on-line ao vivo. & $55,6 \%$ & $41,9 \%$ & $40,3 \%$ & $68,4 \%$ \\
\hline Reportagens e outros textos jornalísticos & $33,3 \%$ & $38,7 \%$ & $37,7 \%$ & $42,1 \%$ \\
\hline $\begin{array}{c}\text { Estou gravando aulas que são postadas na } \\
\text { internet depois. }\end{array}$ & $22,2 \%$ & $37,1 \%$ & $31,2 \%$ & $42,1 \%$ \\
\hline Uso aulas gravadas por outros professores. & $22,2 \%$ & $29,0 \%$ & $29,9 \%$ & $31,6 \%$ \\
\hline $\begin{array}{c}\text { Simulações de fenômenos e processos } \\
\text { naturais em sites (Ex.: PhET) }\end{array}$ & $0,0 \%$ & $1,6 \%$ & $6,5 \%$ & $0,0 \%$ \\
\hline Jogos com finalidade educativa (Ex.: Kahoot) & $22,2 \%$ & $6,5 \%$ & $6,5 \%$ & $10,5 \%$ \\
\hline Outro & $0,00 \%$ & $12,9 \%$ & $11,7 \%$ & $21,1 \%$ \\
\hline
\end{tabular}

Fonte: Autores.

Além disso, esses resultados se relacionam com os dados obtidos na questão "Você já havia tido experiência/formação prévia na produção desse tipo de atividade?", pois $54 \%$ dos respondentes que afirmaram estar produzindo algum tipo de atividade e material para o ensino remoto, não haviam tido experiência e nem formação prévia anterior com atividades remotas. Chama atenção a consolidação de um modelo de trabalho pautado no ensino remoto sem que houvesse negociações prévias e ampla escuta dos professores e gestores que compõem diferentes sistemas de ensino ${ }^{18}$. Sendo esta mais uma faceta da materialização de práticas e retóricas que promovem a subalternização docente, enquanto regulam o ofício do professor,

\footnotetext{
${ }^{18}$ A respeito deste debate, ver a o trabalho intitulado "Em defesa da educação pública comprometida com a igualdade social: porque os trabalhadores não devem aceitar aulas remotas" produzido pelo Coletivo de Estudos em Marxismo e Educação da Universidade Federal do Rio de Janeiro (COLEMARX/UFRJ). Disponível em: http://www.colemarx.com.br/colemarx-ead/. Acesso em 14 de jun. de 2020.
} 
DOI: https://doi.org/10.46667/renbio.v13i1.337

controlam as possibilidades de construção de estratégias didáticas, determinam quais conhecimentos devem ser privilegiados nas ações pedagógicas e produzem efeitos em currículos das escolas e dos cursos de formação de professores (SELLES e ANDRADE, 2018). É possível perceber, ainda que muitos dos materiais utilizados pelos respondentes são de fácil acesso via internet, tais como reportagens, textos jornalísticos e de divulgação científica.

Nesse contexto, cabe-nos indicar que agências sutis e sofisticadas que propiciam maior ingerência do âmbito privado sobre a esfera pública possivelmente estão em curso. É sabido no campo educacional que uma agenda privatista neoliberal, que reúne os interesses do empresariado que lucra a partir de ações que vislumbram a educação brasileira como grande e potencial mercado, têm ganhado impulso desde a década de 1990 (FREITAS, 2014). A comercialização de materiais didáticos padronizados por fundações e grupos empresariais, bem como a realização de parcerias público-privadas para oferecimento de plataformas digitais e suporte, são indícios do quanto a condição de ensino remoto provocado pela pandemia de COVID-19 pode estar sendo aproveitada como ensejo para o fortalecimento de processos gerencialistas e do empresariamento da educação brasileira.

Quando perguntamos aos professores se estavam gostando da experiência de produzir atividades remotas, $61,7 \%$ disseram que parcialmente e este valor se manteve aproximado nos segmentos em que tivemos mais representantes na amostra: Anos Finais do Ensino Fundamental $(64,5 \%)$ e Ensino Médio (68,8\%). De certa forma, embora não tenhamos questionado sobre o lado positivo vivido pelos professores, conseguimos compreender o lado da dificuldade que estas atividades colocaram a eles, durante o período inicial de isolamento social e suspensão das aulas presenciais.

No quadro 4, abaixo, podemos observar as principais dificuldades relatadas pelos respondentes, por segmento de ensino. A conexão lenta e instável de internet, a sobrecarga de trabalho e as dúvidas sobre as melhores abordagens metodológicas para ensinar Ciências e Biologia de forma remota foram as maiores dificuldades relatadas. Estas podem se relacionar a diferentes aspectos, que precisariam ser melhor explorados em pesquisas futuras. Acreditamos, porém, que a falta de um ambiente de trabalho apropriado e de ferramentas necessárias ao ensino remoto, bem como as dificuldades dos professores para o planejamento, a organização e a execução destas atividades, associado às questões psicológicas e logísticas que o isolamento social impõem são fatores que colocariam aos respondentes um sentimento de satisfação parcial com a experiência com a produção de atividades remotas. 
DOI: https://doi.org/10.46667/renbio.v13i1.337

Quadro 4 - dificuldades encontradas por docentes na produção de atividades e materiais didáticos para o ensino remoto por segmento de ensino.

\begin{tabular}{|c|c|c|c|c|}
\hline Dificuldades & $\begin{array}{r}\text { EF1 } \\
(\mathbf{n}=8)\end{array}$ & $\begin{array}{c}\text { EF2 } \\
(n=60)\end{array}$ & $\underset{(n=75)}{\mathbf{E M}}$ & $\begin{array}{c}\text { PV } \\
(n=19)\end{array}$ \\
\hline Minha conexão de internet está lenta e/ou instável. & $66,7 \%$ & $24,2 \%$ & $24,7 \%$ & $36,80 \%$ \\
\hline $\begin{array}{c}\text { A conexão de internet dos estudantes está lenta e/ou } \\
\text { instável. }\end{array}$ & $55,6 \%$ & $40,3 \%$ & $42,9 \%$ & $36,80 \%$ \\
\hline $\begin{array}{c}\text { Meu ambiente doméstico é inapropriado para home } \\
\text { office. }\end{array}$ & $22,2 \%$ & $27,4 \%$ & $28,6 \%$ & $36,80 \%$ \\
\hline Estou com sobrecarga de trabalho. & $44,4 \%$ & $48,4 \%$ & $46,8 \%$ & $36,80 \%$ \\
\hline $\begin{array}{l}\text { Tenho dificuldades no domínio de tecnologias digitais } \\
\text { de informação e comunicação. }\end{array}$ & $22,2 \%$ & $22,6 \%$ & $23,4 \%$ & $36,80 \%$ \\
\hline $\begin{array}{l}\text { Tenho dúvidas sobre as abordagens metodológicas } \\
\text { para ensinar Ciências e Biologia online. }\end{array}$ & $55,6 \%$ & $46,8 \%$ & $40,3 \%$ & $47,40 \%$ \\
\hline $\begin{array}{c}\text { Tenho medo, depressão, ansiedade, tristeza e/ou outras } \\
\text { questões relacionadas à saúde mental. }\end{array}$ & $22,2 \%$ & $21,0 \%$ & $18,2 \%$ & $31,6 \%$ \\
\hline Sinto-me pressionado(a) pela instituição em que atuo. & $22,2 \%$ & $22,6 \%$ & $23,4 \%$ & $15,8 \%$ \\
\hline $\begin{array}{l}\text { Sinto-me inseguro(a) quanto à gravação e uso não } \\
\text { autorizado de minha imagem e voz. }\end{array}$ & $22,2 \%$ & $45,2 \%$ & $29,9 \%$ & $26,3 \%$ \\
\hline Outro & $0,0 \%$ & $9,7 \%$ & $9,1 \%$ & $5,3 \%$ \\
\hline Não tenho nenhuma dificuldade & $0,0 \%$ & $0,0 \%$ & $1,3 \%$ & $0,0 \%$ \\
\hline Ausente (em branco) & $0,0 \%$ & $1,6 \%$ & $5,2 \%$ & $10,5 \%$ \\
\hline
\end{tabular}

Fonte: Autores.

Estas dificuldades levaram, em nosso entendimento, a um sentimento de maior carga de trabalho em relação ao período anterior à quarentena. $\mathrm{O}$ gráfico 2 trata da frequência das respostas para a percepção dos respondentes sobre a carga de trabalho que estavam realizando no período de isolamento social, em relação àquela que desempenhavam antes deste período. A percepção de "maior" carga de trabalho pode estar relacionada a diferentes fatores, como falta de preparo e estrutura do docente para o planejamento e as aulas on-line, o cuidado com a família e a casa, questões psicológicas, entre outras. Contudo, estas razões não foram exploradas pelo questionário em análise (gráfico 2). 
DOI: https://doi.org/10.46667/renbio.v13i1.337

Gráfico 2 - Frequência das respostas ao item "Em comparação com o período anterior à quarentena, você acredita que sua carga de trabalho está", de acordo com o segmento em que atua

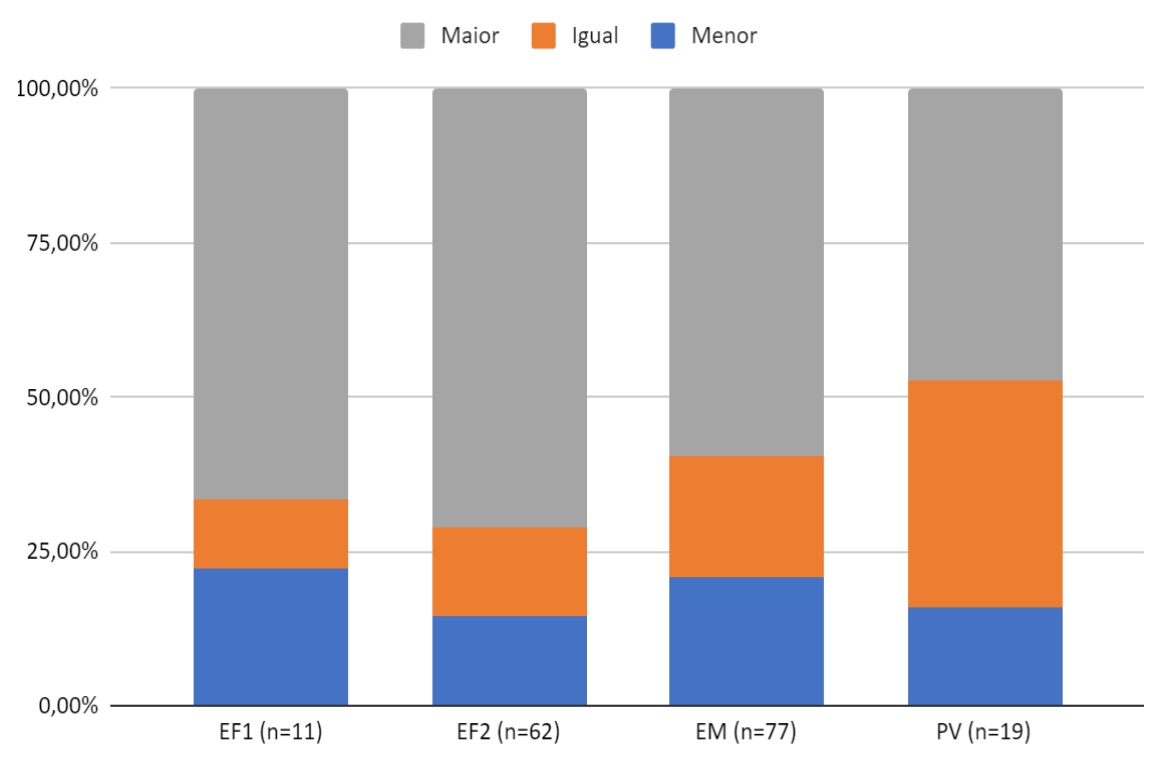

Fonte: Autores.

A última questão da seção sobre atividades remotas solicitava que os respondentes avaliassem em péssimo, ruim, regular, bom ou ótimo os seguintes processos realizados através de atividades remotas de ensino: 1) O ensino de conceitos e conteúdos planejados; 2) A relação entre docentes e estudantes; 3) A avaliação das aprendizagens; 4) A participação dos estudantes; 5) A realização de atividades práticas. Exceto para a realização de atividades práticas (item 5), os professores classificaram como regular os processos didático-pedagógicos das atividades remotas. Em segundo lugar, todos os processos foram classificados como péssimos. Embora acreditemos que esta questão pudesse ser melhor explorada em outra pesquisa, pois nos motiva a saber o porquê destas opiniões e como poderia ser encontrada nas diferentes redes de ensino, entendemos que tais respostas podem estar associadas a certo sentimento de insegurança em função da mudança abrupta para esse novo formato. Como apresentado anteriormente, a maioria dos professores está gostando ao menos em parte dessa experiência, mas se preocupa com questões sobre como ensinar e as abordagens metodológicas on-line inerentes. Neste panorama complexo, estas estão não se encontram dissociadas aos problemas de conexão dos estudantes e de sobrecarga de trabalho.

A pesquisa realizada pelo Instituto Península, citada acima, revelou que no início da suspensão das aulas, devido à pandemia de COVID-19, os professores entrevistados estavam mais preocupados em se manter em casa cuidando de si e dos seus familiares e a disseminar informações seguras para os seus grupos mais próximos, do que interagir remotamente com os alunos, exceto na rede privada, cuja preocupação foi a mesma para estes três fatores. 
Seção 3: ações da SBEnBio

Por fim, na última seção do questionário, foi solicitado aos respondentes que indicassem à Regional 2 da SBEnBio possíveis ações e respectivos assuntos que poderiam ser abordados a fim de auxiliar os professores de Ciências e de Biologia durante a pandemia e a suspensão das aulas presenciais. Em sua maioria, a divulgação de materiais pedagógicos produzidos e cedidos por outros professores e a produção de vídeos com dicas e sugestões para a criação de atividades remotas foram as contribuições mais sugeridas pelos respondentes (quadro 5).

Quadro 5 - Possíveis contribuições da Regional 2 da SBEnBio sugeridas pelos professores.

\begin{tabular}{|l|c|}
\hline \multicolumn{1}{|c|}{ Contribuição da SBEnBio - Regional 2 } & $\%$ \\
\hline $\begin{array}{l}\text { Divulgação de materiais pedagógicos produzidos e cedidos por professores e } \\
\text { professoras. }\end{array}$ & 74,0 \\
\hline Produção de vídeos com dicas e sugestões para a criação de atividades remotas. & 71,9 \\
\hline $\begin{array}{l}\text { Realização de "lives" (transmissões ao vivo pela internet) para debater assuntos } \\
\text { contemporâneos e subsidiar a atuação docente. }\end{array}$ & 53,6 \\
\hline Promoção de encontros virtuais para partilhas de experiências docentes. & 49,0 \\
\hline Outros & 3,5 \\
\hline
\end{tabular}

Fonte: Autores.

Para nós, tais contribuições relacionadas aos aspectos didáticos-pedagógicos e metodológicos do ensino de Ciências e de Biologia, também estiveram contempladas pela questão "Qual assunto você gostaria de que fosse abordado/discutido em atividades promovidas pela SBEnBio - Regional 2 durante esse período?”. Essa era uma questão aberta, sendo possível dar mais de uma resposta ou deixar esse item em branco. Desse modo, foram produzidas 146 respostas diferentes pelos respondentes. Foi realizada uma recodificação destas respostas, de modo a facilitar a análise, chegando às categorias indicadas no quadro 6. 
DOI: https://doi.org/10.46667/renbio.v13i1.337

Quadro 6 - Assuntos sugeridos para serem abordados pela Regional 2 da SBEnBio.

\begin{tabular}{|c|c|}
\hline Assuntos & Contagem $^{\mathbf{1 9}}$ \\
\hline $\begin{array}{c}\text { Ensino (conteúdos/metodologias) através de } \\
\text { atividades remotas }\end{array}$ & 43 \\
\hline Acesso aos meios digitais & 10 \\
\hline Virologia e coronavírus & 10 \\
\hline Pandemia e pós-pandemia & 9 \\
\hline Avaliação através de atividades remotas & 7 \\
\hline Genética e Biotecnologia & 7 \\
\hline Saúde mental docente & 4 \\
\hline Impactos do isolamento social sobre a saúde & 3 \\
\hline humana & 3 \\
\hline Condições sanitárias e pandemia & 4 \\
\hline Valor do professor & \\
\hline
\end{tabular}

Fonte: Autores.

Acreditamos que estas demandas dos respondentes trazidas à Regional 2 da SBEnBio, devem-se ao menos a dois fatores. Um deles pode estar relacionado ao caráter intrínseco da profissão docente, que é aquele de ter uma preocupação com o "como" e "o que" ensinar em Ciências e Biologia, ainda que saibamos que conteúdo e forma são indissociáveis e carregam consigo finalidades de ensino e concepções que dão base e sustentação para as metodologias de ensino. Frente ao contexto atual de pandemia, isolamento social e suspensão de aulas presenciais, somados a certo aligeiramento de decisões para o planejamento e execução do ensino remoto, entendemos que os professores participantes desta pesquisa sentem uma necessidade legítima de auxílio para pensar e executar o ensino remoto, tarefa acompanhada de uma percepção de muitos não foram formados para atuar profissionalmente com este tipo de abordagem. Como o levantamento aponta, foi indicada uma forte tendência de produção de atividades remotas pelos docentes, mas a maioria não teve experiência prévia ou formação anterior para isso. Estão aprendendo na "prática" diante do atual contexto.

Outro fator que não podemos desconsiderar é que a maioria dos respondentes desta pesquisa (85,6\%) não é associada à SBEnBio e, por este motivo, eles desconhecem as ações desenvolvidas pela Associação, como: espaços de participação e difusão de debates sobre políticas educacionais para formação de professores e o ensino de Ciências e Biologia; divulgação e apoio a eventos que mobilizam discussões sobre Ensino de Ciências e Biologia e suas relações entre Pesquisa e Ensino; promoção de debates sobre propostas e estratégias

\footnotetext{
${ }^{19}$ Número absoluto de vezes que essas categorias foram citadas pelos respondentes.
} 
DOI: https://doi.org/10.46667/renbio.v13i1.337

formativas para professores da Educação Básica, ampliando a divulgação e o sentido da SBEnBio como espaço de formação docente continuada e de fortalecimento de coletividades profissionais. Neste sentido, com estes resultados, vemos a necessidade de ampliar cada vez mais nossas ações para que novos associados se filiem e contribuam para o fortalecimento do ensino e da pesquisa em educação em Ciências e Biologia, em todos os segmentos e modalidades de ensino das redes pública e privada.

\section{Considerações finais}

De acordo com os resultados da pesquisa, podemos tecer considerações sobre três aspectos principais: a maioria dos docentes não se sente segura e confortável diante das questões metodológicas do ensino remoto pautado no uso de tecnologias digitais de informação e comunicação, também por conta de problemas como a má qualidade das conexões e as oscilações dos serviços de internet; os cotidianos domésticos se fazem presentes sobremaneira no momento das aulas virtuais; as atividades de ensino remotas permitem maior controle e regulação da atividade docente.

Com relação à primeira consideração, apuramos que os professores assumem que precisam lidar com as atividades de ensino remotas como uma demanda incontornável: diante da conjuntura pandêmica e do cenário de precarização da carreira docente, com consequente perda de autonomia, que vem se desenhando há tempos, muito pouco há o que fazer a não ser tomar para si esta tarefa desafiadora. Tal demanda tem interpelado também os processos formativos iniciais e continuados dos professores, gerando questionamentos sobre o espaço que as metodologias voltadas à utilização didática de tecnologias digitais de informação e comunicação vem recebendo nesse bojo.

Historicamente, os currículos dos cursos de formação de professores de Ciências e Biologia vêm sendo atravessados por múltiplas demandas que depositam sobre as disciplinas pedagógicas e os estágios supervisionados a responsabilidade de fornecerem subsídios suficientes para o bom desempenho docente ao longo de décadas de trabalho, segundo sinalizam e discutem Vilela, Ayres e Selles (2020). Neste sentido, cabe-nos indagar quais os impactos futuros nas práticas e políticas de desenvolvimento profissional de professores. Contudo, sabendo que tensões plurais permeiam os cursos de Licenciatura em Ciências e Biológicas, ora aproximando-os das dimensões profissionais em detrimento das acadêmicas, ora caminhando em sentido oposto (AYRES, 2009), é possível que o fomento a abordagens didáticas híbridas entre as atividades tradicionalmente realizadas nas escolas e as incursões pelas realidades virtuais com o apoio de dispositivos digitais sob uma perspectiva mais instrumental devem permanecer com certo destaque, pelo menos no futuro próximo.

Portanto, ainda que questões sobre a saúde e condições de trabalho docente tenham sido ressaltadas houve a reivindicação de três quartos dos docentes para que a Regional 2 viabilizasse a socialização de materiais pedagógicos e de vídeos com dicas para gravação de aulas remotas, deixando visível que as atividades de ensino remotas já são uma realidade e os docentes pedem apoio para planejá-las, avaliá-las e conduzi-las. Convém lembrar ainda que a 
DOI: https://doi.org/10.46667/renbio.v13i1.337

maioria dos respondentes desta pesquisa $(80,2 \%)$ são professores das redes públicas estadual e privada atuantes no estado do Rio de Janeiro (gráfico 1). Na rede estadual do Rio de Janeiro, os professores utilizam uma plataforma para atividades on-line, de propriedade da Google, e são orientados a estar "logados", isto é, conectados à internet, e em contato com as turmas no horário de suas aulas presenciais. Na rede privada, o que se tem visto é que os professores têm usado estratégias diversas, muitas vezes tendo eles próprios que produzir, gravar e editar videoaulas em suas casas. Além disso, a má qualidade e a limitação de acesso de serviços de internet, é um problema frequente a ser contornado pelos professores.

No que se refere aos cotidianos domésticos e à dinâmica de trabalho docente homeoffice o limite entre as atribuições familiares e profissionais fica pouco definido. Confinados em um mesmo ambiente, é frequente que as dinâmicas domésticas causem transtornos durante o expediente de trabalho do docente e vice-versa. Além disso, muitas vezes o instrumento de trabalho, o computador, precisa ser partilhado pela família. Não à toa os respondentes disseram ter a sensação de maior carga de trabalho neste período de isolamento social, em comparação com o trabalho presencial.

É interessante notar que, em nossa pesquisa, a maior parte dos respondentes informou um aumento no investimento de tempo para planejamento e execução das atividades remotas, ampliando a carga horária semanal de trabalho que tinham antes do início das atividades remotas. A realidade de trabalho de professores e professoras são as jornadas duplas ou triplas, sendo que muitos têm matrícula em mais de uma escola ou rede de ensino. É importante chamar a atenção ainda para o fato de que a maioria dos docentes da educação básica são mulheres (VIANNA, 2002), que são também donas de casa e/ou mães e sobre elas recaem a maioria das tarefas domésticas e da educação dos filhos. Essa realidade é agravada durante a pandemia do coronavírus, como ressalta Boaventura de Souza Santos (2020), sendo a mulher quem mais sofre stress, com crianças e outros familiares em casa. O machismo impede que as tarefas do lar sejam divididas, tendo a mulher que acumular as funções do espaço-tempo doméstico com as múltiplas demandas do trabalho.

Com relação ao controle da atividade docente, a experiência nos mostra que as redes sociais e a internet nos trouxeram uma série de benefícios e facilidades, mas também vêm permitindo maior controle de nossas vidas, de nosso trabalho e nos toma muito mais tempo, visto que as mensagens e demandas de trabalho pouco respeitam horários e espaços privados. O acúmulo de responsabilidades, que não mais somente os saberes pedagógicos, mas também a operacionalização de recursos tecnológicos ocasiona um aumento de exigências e responsabilidades sobre o professor e seu esgotamento físico e emocional (ESTEVE, 2014).

Isto merece especial atenção, pois como se percebe nas respostas, tal processo acaba por causar abalos na saúde mental dos mesmos como: "medo", "depressão", "ansiedade" e "tristeza". Nessa direção, Esteve (2014, p. 100) ressalta que a "crise de identidade" gerada mediante mudanças no sistema de ensino leva a distintas reações dos professores, como "inibição", "ceticismo" e "medo". Como consequência, o docente põe em xeque a sua prática, revelando-se o que julgam ser lacunas de conteúdo ou das metodologias de ensino. Para esses, 
DOI: https://doi.org/10.46667/renbio.v13i1.337

o ensino é vivido com ansiedade e depressão seja pela frustração perante a carência de recursos adequados para levar à prática o tipo de ensino que, idealmente, gostariam de fazer, seja por culpabilizarem-se pela incapacidade de levar à prática os seus ideais pedagógicos.

Ressaltamos também que, ao procurarmos outros artigos para que pudéssemos tecer diálogos sobre os desdobramentos que a pandemia trouxe para a educação brasileira, tivemos dificuldade de encontrá-los. Durante a redação desse manuscrito, consultamos acervos como o da Scientific Electronic Library Online (SciELO) e o Portal de Periódicos CAPES, mas não localizamos trabalhos nacionais sobre o assunto. Destarte, acreditamos que este texto contribui para as reflexões no campo educacional, especialmente para o Ensino de Ciências e Biologia, abrindo espaço para outras interlocuções em tempos dificilmente imaginados, que nos chamam a repensarmos nossas práticas docentes e de pesquisa.

As reflexões trazidas neste trabalho reafirmam o compromisso de nossa Associação Brasileira de Ensino de Biologia e, mais especificamente, da Regional 2, em trabalhar na escuta desses docentes, ampliando e diversificando os canais de comunicação e, assim, promovendo uma troca de experiências formativas. Como desdobramento desse levantamento já tivemos, até o momento do fechamento desta escrita, dois debates transmitidos ao vivo ${ }^{20}$, que têm garantido espaço de participação e difusão de debates relevantes para a educação e o ensino de Ciências e Biologia, especialmente em tempos de pandemia. Além disso, a Regional tem empreendido um esforço para divulgar materiais didáticos e oportunidades de aperfeiçoamento profissional on-line aos seus associados e aos participantes da pesquisa supracitadas via $e$-mail, bem como ao público em geral via rede social. Como perspectiva futura, temos apostado na integração do trabalho com outras ações capitaneadas por outras regionais e pela diretoria executiva nacional da SBEnBio. Em busca de mais parcerias, temos empreendido e consolidado diálogos com outras associações e coletivos docentes formados por professores da Educação Básica e/ou do Ensino Superior. Buscamos desse modo, atuar com segurança em diferentes frentes, cultivando afetos e esperanças, permanecendo fiéis às demandas docentes e às conclusões que puderam ser construídas a partir do levamento aqui focalizado.

\section{Agradecimentos}

Agradecemos aos colegas professores de Ciências e Biologia que participaram da pesquisa apresentada, assim como àqueles que contribuíram para sua divulgação e publicização.

\footnotetext{
${ }^{20}$ Os debates "Ensino de Ciências e Biologia na pandemia: o que os docentes nos contam?" e "O que cabe no ensino remoto?" foram transmitidos ao vivo e contaram com a participação do público pelo canal da Regional 2 da SBEnBio na plataforma Youtube, denominado sbenbio2encontros. O canal pode ser acessado em: <https://www.youtube.com/c/sbenbio2encontros>.
} 
DOI: https://doi.org/10.46667/renbio.v13i1.337

\section{Referências}

AYRES, A. C. M. Formação docente: tensões entre dimensões profissional e acadêmica nos cursos de licenciatura em Ciências Biológicas. In: SELLES, S. E., FERREIRA, M. S., BARZANO, M. A. L.; SILVA, E. P. Q. (Org.). Ensino de Biologia: histórias, saberes e práticas formativas. Uberlândia: EDUFU, 2009, p. 71-86.

CARMO, E. M.; SELLES, S. E. "Modos de Fazer" elaborados por professores de biologia como produção de conhecimento escolar. Revista Brasileira de Pesquisa em Educação em Ciências, v. 1, 2018, p. 269-299. https://doi.org/10.28976/1984-2686rbpec2018181269

ESTEVE, J. M. Mudanças sociais e função docente. In: NÓVOA, A. (Org.). Profisssão professor. Porto editora, 2014, p. 93-124.

FREITAS, L. C. Os reformadores empresariais da educação e a disputa pelo controle do processo pedagógico na escola. Educação \& Sociedade, v. 35, 2014, p. 1085-1114. https://doi.org/10.1590/ES0101-73302014143817

INSTITUTO PENÍNSULA. Sentimento e percepção dos professores brasileiros nos diferentes estágios do Coronavírus no Brasil. Disponível em: https://www.institutopeninsula.org.br/wp-content/uploads/2020/03/Pulso-Covid-19_Instituto-Peni\%CC\%81nsula.pdf. Acesso em jun. de 2020.

SANTOS, B. S. A cruel pedagogia do vírus. Coimbra: Almedina, 2020.

SELLES, S. E.; ANDRADE, E. P. Políticas Curriculares e subalternização do trabalho docente. Educação em Foco, v. 21, 2016, p. 39-64. https://doi.org/10.22195/2447524620162119654

SELLES, S. E.; ANDRADE, E. P. Políticas de currículo e formação docente em tempos sombrios. In: CACHAPUZ, A.; SHIGUNOV NETO, A.; FORTUNATO, I. (Org.). Formação inicial e continuada de professores de Ciências: o que se pesquisa no Brasil, Portugal e Espanha. São Paulo: Hipóteses, 2018. v. 1, p. 77-96.

TARDIF, M. Saberes docentes e formação profissional. Petrópolis: Vozes, 2014.

VIANnA, C. O sexo e o gênero da docência. Cadernos Pagu, Campinas, v. 17/18, 2002, p. 81-104. https://doi.org/10.1590/S0104-83332002000100003

VILELA, M. L.; AYRES, A. C. M.; SELLES, S. E. Formação de professores de ciências e biologia: legislações e profissionalidade docente. In: VILELA, M. L.; MENDES, R. R. L.; PINHÃO, F. L.; RIOS, N. T (Org.). Aqui também tem currículo! Saberes em diálogo no ensino de Biologia. Curitiba: Appris, 2020, p. 101-120.

VINUTO, J. A amostragem em Bola de Neve na pesquisa qualitativa: um debate em aberto. Temáticas, v. 44, 2015. p. 201-218.

https://doi.org/10.20396/tem\%C3\%A1ticas.v22i44.10977 